\title{
Tolerância à dor no infarto do miocárdio*
}

\author{
Pain tolerance during myocardium infarction
}

Tolerancia al dolor en infarto del miocárdio

\author{
Fernanda Carneiro Mussi ${ }^{1}$, Álvaro Pereira ${ }^{2}$
}

\begin{abstract}
RESUMO
Objetivo: Analisar a tolerância à dor como sintoma prodrômico do infarto do miocárdio na perspectiva dos gêneros masculino e feminino em pacientes que vivenciaram esse evento cardiovascular. Métodos: Estudo exploratório de natureza quanti-qualitativa. Entrevistou-se 43 mulheres e 54 homens em hospital público. Os dados sóciodemográficos foram analisados em percentuais e os qualitativos com base na análise de conteúdo e da categoria gênero. Resultados: A mediana de idade para homens foi 55,3 e mulheres de 61,5 anos. Predominou para os gêneros a baixa escolaridade e inatividade profissional. Os homens tinham renda familiar maior e viviam mais em companhia de alguém. Evidenciou-se que homens e mulheres demonstraram igualmente enfrentamento e resistência à dor, visando manter o controle da própria existência e reproduzindo construções sociais sobre o masculino e o feminino em suas vidas cotidianas. Conclusão: O desafio profissional é atuar no plano simbólico dos gêneros para reduzir o retardo na decisão de buscar atenção médica e possibilitar os benefícios imediatos das terapias de reperfusão coronária.
\end{abstract}

Descritores: Infarto do miocárdio; Identidade de gênero; Dor no peito.

\begin{abstract}
Purpose: To evaluate pain tolerance as a prodromic symptom in men and women who had a myocardium infarction. Methods: This was a quantitative-qualitative exploratory study with 43 women and 54 men from a public hospital. Demographic data were analyzed with percentages and qualitative data were analyzed with content analysis according to gender. Results: The men's mean age was 55.3 years. The women's mean age was 61.5 years. Both genders had low educational level and professional inactivity. Men lived with a significant other and had higher family income than women. There was no difference regarding pain tolerance between men and women. Both men and women tried to maintain control over their life and to reproduce social constructions in daily life regarding being male and female. Conclusion: Heath care professional actions for the prevention of delaying seeking medical care for coronary perfusion by both male and female is challenging.
\end{abstract}

Key Words: Myocardium infarction; Gender identity; Chest pain.

\section{RESUMEN}

Objetivo: Analizar la tolerancia al dolor como síntoma prodrómico del infarto del miocardio en la perspectiva de los géneros masculino y femenino en pacientes que experimentaron ese evento cardiovascular. Métodos: Estudio exploratorio de naturaleza cuantitativa cualitativa. Se entrevistaron 43 mujeres y 54 hombres en un hospital público. Los datos sociodemográficos fueron analizados en porcentajes y los cualitativos con base en el análisis de contenido y de la categoría género. Resultados: El promedio de edad para hombres fue 55,3 y mujeres de 61,5 años. Predominó para los dos géneros la baja escolaridad e inactividad profesional. Los hombres tenían renta familiar mayor y vivían más en compañía de alguien. Se evidenció que los hombres y mujeres demostraron igualmente enfrentamiento y resistencia al dolor, con el objetivo de mantener el control de la propia existencia y reproduciendo construcciones sociales sobre lo masculino y lo femenino en sus vidas cotidianas. Conclusión: El desafío profesional es actuar en el plano simbólico de los géneros para reducir el atraso en la decisión de buscar atención médica y posibilitar los beneficios inmediatos de las terapias de reperfusión coronaria. Palabras clave: Infarto del miocardio; Identidad de género; Dolor en el pecho.

*Trabalho desenvolvido com apoio da Fundação de Amparo a Pesquisa do Estado da Babia - FAPESB - Salvador (BA), Brasil.

${ }^{1}$ Doutora em Enfermagem. Professora Adjunto IV da Escola de Enfermagem da Universidade Federal da Babia - Salvador (BA), Brasil.

${ }^{2}$ Doutor em Enfermagem. Professor Adjunto IV da Escola de Enfermagem da Universidade Federal da Babia - Salvador (BA), Brasil. 


\section{INTRODUÇÃO}

As doenças cardiovasculares, que incluem o infarto do miocárdio (IAM), representam as principais causas de morbidade e mortalidade no mundo. No Brasil, no ano 2007, o número de óbitos por IAM foi de 71.997, correspondendo a um total de $6,9 \%$ do total de mortes no referido ano ${ }^{(1)}$.

A despeito da expressiva redução da letalidade hospitalar do IAM, decorrente da introdução de novas tecnologias, a questão da mortalidade pré-hospitalar permanece praticamente inalterada, com níveis semelhantes aos de 40 anos atrás, desafiando as autoridades de saúde pública, ceifando milhares de vidas em plena idade produtiva e acarretando inúmeros prejuízos à sociedade(2).

Sabe-se que dois terços das mortes súbitas por doenças coronarianas ocorrem fora do hospital e a maioria dentro de duas horas após o início dos sintomas cardiovasculares. A mortalidade pode ser minimizada mediante atendimento rápido após o início dos sintomas ${ }^{(2)}$. Todavia, um obstáculo importante para o benefício da terapia de reperfusão coronária continua sendo o atraso na sua instituição. É sabido que pelo menos $60 \%$ das pessoas que sofrem IAM apresentam sinais e sintomas prodrômicos, mas nem todos os reconhecem e/ou hesitam em aceitar a gravidade de sua condição, retardando, assim, o socorro médico ${ }^{(3-4)}$, em média de três a quatro horas após o início dos seus sintomas ${ }^{(5)}$.

Entre os vários fatores destacados na literatura que influenciam a demora na decisão para a busca de atendimento médico incluem-se aspectos clínicos e a percepção e os sentidos atribuídos à dor entre os gêneros masculino e feminino( ${ }^{()}$. As mulheres com IAM podem ter menor taxa de dor torácica ou de sudorese, quando comparadas aos homens, e mais frequência de dispnéia ${ }^{(7)}$. Constatou-se, também, que homens e mulheres que sofreram IAM hesitaram na procura de socorro médico e agiram com seus próprios recursos para tentar sanar o mal que os afligia, enquanto não se sentiram dominados pela dor e mobilizados pelo medo de $\operatorname{morrer}^{(4-8)}$.

$\mathrm{Na}$ cultura brasileira, são escassas as pesquisas que se preocupam em entender os motivos que influenciam o retardo da decisão de indivíduos para procurar atendimento médico face à dor como sintoma prodrômico do IAM.

Torna-se importante considerar o enfoque do gênero aplicado às questões de saúde e, assim, no caso específico deste estudo, entender a influência das características e construções de gênero no processo de tolerância a dor como sintoma prodrômico do IAM. Entende-se que a categoria gênero dá o devido destaque às características socialmente construídas, que constituem as construções sociais sobre o masculino e o feminino nas distintas culturas. Nesse sentido, gênero é compreendido como a rede de traços de personalidade, atitudes, sentimentos, valores, condutas, atividades que, através de um processo de construção social, diferencia homens e mulheres ${ }^{(9)}$. A categoria gênero, que teve sua origem no movimento feminista, tem a "[...] preocupação de desnaturalizar e dessubstancializar a noção de feminino e masculino nas análises que vinculam os papéis sexuais ao seu substrato biológico"(10).

Assim, construções sociais sobre o masculino e o feminino podem estar implicadas nas atitudes das pessoas no que tange à própria saúde, ou seja, fatores relacionados aos condicionantes de gênero, além de influenciar a frequência de ocorrência da doença, seu curso e a mortalidade, podem alterar a conduta face a mesma e o uso dos serviços de saúde.

Nesse sentido, fazem-se necessários estudos sobre os fatores relacionados ao gênero, no que se refere a tolerância à dor como sintoma prodrômico do IAM para que se possa reconhecer melhor e intervir sobre os motivos da demora para a busca de atendimento médico e, então, promover a valorização do tratamento precoce.

A dor vem sendo um sinal vital muito discutido na atualidade científica médica e, como tal, merece ser analisada também pela perspectiva antropológica do gênero, uma vez que sofre a interferência de raízes socioculturais que determinam diferentes significados, formas de tolerância e enfrentamento entre os gêneros humanos.

Com base no exposto, determinou-se como objetivo deste estudo: Analisar a tolerância à dor como sintoma prodrômico do IAM na perspectiva dos gêneros masculino e feminino em pacientes que vivenciaram esse evento cardiovascular.

\section{MÉTODOS}

Trata-se de um estudo de natureza quantitativa e qualitativa do tipo exploratório descritivo, realizado em um hospital público, de ensino, que atende prioritariamente à clientela proveniente do Sistema Único de Saúde, situado em Salvador (BA), tendo por sujeitos mulheres e homens adultos, em condições de serem entrevistados, que sofreram IAM com dor e que demandou atendimento médico.

O projeto foi aprovado pelo Comitê de Ética da instituição referida. Mediante assinatura do Termo de Consentimento Livre e Esclarecido, os participantes concordaram em participar da pesquisa. Foi-lhes assegurado o esclarecimento dos objetivos da investigação, o sigilo da identidade pessoal e o direito de abandonar o estudo a qualquer tempo que o desejassem.

Para a coleta de dados foi elaborado um formulário contendo, na primeira parte, dados de identificação dos participantes e, na segunda, questões abertas e semiestruturadas, a exemplo de: Fale-me sobre a dor que você sentiu. O que você fez na hora da dor?

A entrevista foi gravada nas unidades de internação e coronariana e no ambulatório do locus de estudo. Os dados foram transcritos na íntegra e analisados com base no referencial teórico sobre a categoria gênero e mediante emprego da técnica de análise de dados qualitativos, a saber: na primeira fase da análise, as respostas foram examinadas minuciosamente, para extrair os núcleos de sentido. Pelo processo de comparação, os núcleos de sentido identificados foram agrupados por similaridades e diferenças, formando as categorias. 
O número de participantes não foi predeterminado, mas resultante do processo de análise, que visou alcançar a representatividade das categorias relacionadas à compreensão das razões para tolerância à dor, que emergiram do discurso dos sujeitos, de modo a acumular evidências, dar maior densidade ao fenômeno em estudo e obter-se a saturação teórica das categorias.

Os dados de caracterização dos participantes (43 mulhres e 54 homens) foram analisados com base em percentuais e pelo Teste Exato de Fisher para estudar a dependência entre variáveis. $\mathrm{O}$ nível de significância estatística para decisão dos testes foi de $5 \%(\mathrm{p}<0,05)$.

\section{RESULTADOS}

\section{Perfil sociodemográfico dos participantes}

Os 97 participantes foram predominantemente provenientes de Salvador e Região Metropolitana (59,8\%), e também de outras regiões da Bahia (38,1\%). Apenas 10,3\% declararamse brancos, todos os demais consideraram-se negros, pardos e morenos.

Dos 54 homens e das 43 mulheres apenas 19,6\% encontravam-se na faixa etária jovem para exposição ao IAM, ou seja, até 50 anos. Os demais estavam entre 50 e 65 anos (49,5\%) ou acima de 65 anos (30,9\%). A mediana de idade para os homens foi 55,3 e para as mulheres de 61,5 anos. Portanto, as mulheres infartaram mais tarde que os homens $(p=0,038)$, confirmando os achados na literatura sobre a incidência de infarto de acordo com o gênero.

Mais da metade dos participantes eram casados(as) ou viviam com companheiro(a) (59,8\%), seguidos dos separados, viúvos e solteiros (40,2\%). Ao comparar-se homens e mulheres, verificouse maior frequência de homens com companheira $(p=0,001)$. Vale ressaltar que nas faixas etárias acima de 50 anos, a maioria das mulheres já está sozinha, seja por morte dos companheiros, seja por separação, com poucas possibilidades de refazerem sua vida conjugal, ou mesmo por opção de não ter companheiro, o que justifica encontrarmos a maioria nesta situação.

A escolaridade baixa prevaleceu entre homens e mulheres, pois $17 \%$ dos sujeitos eram analfabetos e 57,7\% não possuíam o primeiro grau completo. As variáveis gênero e escolaridade foram independentes $(p=0,809)$.

Quanto à atividade profissional, 53,3\% dos entrevistados eram inativos devido a aposentadoria, afastamento ou pensão da Previdência Social ou, ainda, situação de desemprego. As variáveis gênero e atividade profissional foram independentes $(p=0,776)$.

No que se refere à renda familiar, 61,9\% recebiam até cinco salários mínimos e a renda dos homens foi maior em relação à das mulheres $(\mathrm{p}=0,005)$, prevalecendo, especialmente para elas, a baixa renda, isto é, até três salários mínimos.

A maioria dos participantes não teve infarto prévio $(83,5 \%)$ e o número de eventos não foi associado ao gênero $(\mathrm{p}=0,249)$. A maioria das ocorrências teve início no domicílio $(72,2 \%)$, seguidas daquelas que ocorreram em via pública $(22,7 \%)$ e no ambiente de trabalho (5,2\%), não havendo diferença estatisticamente significante entre local de ocorrência do IAM e gênero.

Tolerância à dor do infarto na perspectiva do gênero

A análise dos dados evidenciou que tanto homens quanto mulheres demonstraram formas de enfrentamento e resistência à dor, visando manter o controle da própria existência, e reproduzindo construções sociais sobre o masculino e o feminino na sua vida cotidiana. Emergiram, assim, duas categorias, a seguir apresentadas.

\section{Das construções sociais sobre o masculino na resistência à dor}

Várias ações identificadas nos relatos de homens mostraram resistência à dor, não obstante o sofrimento gerado por ela, e expressaram a valorização da força, vigor, coragem, determinação pela manutenção de sua condição socioeconômica. A resistência foi evidenciada pela tentativa de tolerar a dor, de não interromper atividades usuais, de evitar o afastamento do convívio social e do mundo do trabalho e, consequentemente, de adiar a procura de atendimento médico. A princípio, foi difícil admitir a possibilidade de que algo extraordinário estava acontecendo e impedindo a realização da vida cotidiana. Eles testaram seus limites de tolerância à dor até o limiar do insuportável. Tais interpretações são ilustradas com os discursos que se seguem:

Eu comecei a primeira dor no domingo. E ai fiz uma viajem e já de volta, na parte da tarde, comecei a me preocupar. Tinha uma ladeira grande, eu disse, eu não vou subir essa ladeira, porque acredito que en vou morrer antes que ela termine, mas Deus favoreceu que en continuei subindo, terminei de subir, sai do caminhão e fui no mato para respirar e ver se melhorava a situação. Ai, depois continuei, cheguei em Morro do Chapéu, encontrei um amigo. O rapaz, perguntou: o que você tem? Eu disse: rapaz eu tô ruim, eu tô morto, vou morrer, eu tô com uma dor no peito e do peito passa para os braços, e aquele cansaço doendo, das juntas para baixo. Ele disse: V amos no médico rapaz: Eu disse: Rapaz eu não vou não, eu vou pra casa. [...] Cheguei lá no posto fiquei conversando com os amigos. Ai eu disse: Não vou para casa não, um cara que vive de "frete", armei a rede na cabine do caminhão, me deitei, quando foi umas doze horas começou a confusão num bar, ai me meti no meio, quando terminou voltei para o posto e me deitei de novo na rede. Quando voltei, já voltei aperreado. Falei com o bombeiro: rapaz en vou morrer... O que é rapaz? Eu tô com uma dor aqui muito perigosa. Vamos ao médico? Rapaz, eu estou de acordo. Ai um amigo men me levou para o hospital.

Eu estava cavando uns buracos para colocar umas madeiras em cima e eram oito buracos. Até no sétimo, já estava no último buraco, e eu sentia que tinha que parar, mas en não parava. Eu disse: Não, só vou parar quando terminar o último, né. Ai eu não aguentei ...

Pô, na hora da dor, eu quis ficar com os filhos, entendeu? Como se não tivesse acontecendo nada, mas... tanto é que eu fui 
tomar um banho, pra ver se, se a dor passava, que eu também não pensava que era infarto. Eu até fiquei assim pra não ir "pro" médico, mas depois que a dor começon mesmo, ai que en vi que não tinha jeito. [...] No caso, quando eu senti a dor, que eu vi que "tava" ficando forte... ai eu vi que eu não tinha mais condições nem de pegar um transporte, um coletivo no caso. Ai eu, disse: É, ai liguei pro meu cunhado, ele mora perto; ele tem carro e ele veio rápido. E me levou.

Alguns homens demonstraram resistência à dor ocultando-a, evitando revelar seus limites e preocupar familiares:

Tava dormindo. As vezes, de madrugada ou pela manhã, en sonhava com qualquer coisa, no sonho vinha aquela dorzinha fina, aquele queimor no peito. Ai não dormia mais, descia pra garagem e ficava lá dormindo até dar 3 horas, dentro do carro, pra mulher não se preocupar comigo, e eu ir trabalbar...

Eu molhei as plantas, ai eu entrei pra dentro de casa, tomei café. Aí, quando eu não aguentei sentei no sofá. Ai minha neta disse assim: Meu avô, o senhor "tá" quieto é porque "tá" sentindo alguma coisa? Eu disse: Não minha filha, "to" não, que nada. Sentia dor, mas não dizia, prá não perturbar o sossego dos outros. [pensando e barganhando com Deus] Meu Deus, o que é que eu vou fazer? Dizer pro men filho, ele vai ficar apavorado. A coisa tá ruim, vou ficar quieto até ver o que Deus quer comigo, se não tiver nada eu viajo, se tiver nós ficamos. Pronto, meu pensamento era esse...

Constatou-se que a resistência à dor foi também evidenciada pela tentativa de suportá-la, uma vez que, para alguns, o verdadeiro homem não berra de dor. Além de ocultá-la, eles também procuraram naturalizá-la, fazer tentativas para melhorar e manter atividades, mesmo com dor e, de modo geral, só procuraram atendimento médico diante da dor insuportável, ao sentirem-se vencidos pelo sofrimento intolerável.

Eu tive infarto, eu... Sai daqui, fui pra casa, quando foi umas sete horas pra oito horas me deu aquela dor, aquela dor no peito, "né"? E ai me apertando aquilo. Depois eu amanheci o dia. A noite toda com dor. Quando deu de manhã, que eu não aguentava, foi que eu sai com a mão assim, pedindo socorro ao vizinho.

Eu sustento muito a dor, eu não berro com muita bobagem não...

As duas primeiras vezes da dor, uma "tava" vindo "pra" casa, seis e meia, aí passando no campo, atravessando o campo, pra ir pra casa, de bicicleta. Ai eu parei a bicicleta, sentei no chão e levei uns dez a quinze minutos sentado. Até aliviar. Quando aliviou, eu fui embora "pra" casa normal. No outro dia, eu fui mexer no lavatório da vizinha, a dor também tornou a apertar. Ela veio com uma frequência maior. Ai eu fui em casa, liguei o ventilador e fiquei na frente do ventilador; ai aliviou a dor de novo. Também não falei com ninguém... Eu não ligava muito, eu não ligava não.

Eu suporto qualquer dor, qualquer eu suporto. Essa foi terrivel, foi a pior que eu já senti mesmo, mas, se eu abrir a boca para dizer tá doendo, é porque eu acho que muita gente já tinha embarcado, viu, já tinha gritado de dor e eu não grito não, eu comendo aquela dor aqui sozinho... Passei o sábado e o domingo sem procurar atendimento nenhum. Eu só vim, eu vim no domingo onze e meia para meia noite.

\section{Das construções sobre a resistência à dor por mulheres}

Como não houve distinção acerca da resistência à dor por parte dos gêneros, o estudo deu destaque às construções sociais sobre as formas de enfrentamento e a tolerância à dor por parte das mulheres, tal como foi feito para os homens.

Várias mulheres revelaram que dor é para ser tolerada, restando a elas gemer ou tentar aliviá-la com recursos próprios. Suportando a dor, ocultando-a, nem sempre conhecendo a natureza real dos sintomas, esperando e fazendo tentativas para melhorar, algumas retardaram a consideração da gravidade de sua condição e a busca de atenção médica, como ilustram os depoimentos a seguir:

A dor foi muita. Ela doía aqui em cima do peito, descia aqui para esse ombro, para o braço. Ai eu caminhava até de quatro, para poder dar uma aliviada; eu ficava sem fôlego, pelejava, depois en saía assim, de quatro, gritando: ai, ai, ai, para ver se o fôlego vinha. E nada! Aí en ficava o dia todinho deitada com esse braço aqui e esse ombro doendo. Eu não sei não... Eu sou mulher que sofro só; não gosto de ninguém por perto. Não sou de dar trabalho a ninguém. Seja feita a vontade de Deus, só conforto em Deus..

Minha filha, eu tô sentindo isso há mais de seis meses. Antes eu pensava, assim, que era qualquer dorzinha. Não ligava, sabe. Seis meses antes (do infarto), sentia aquela dor, sentia aquela dor. Deitava, dormia. As minhas filhas sempre diriam, né: é um mal deitar, não mamãe, não sei o quê, vá ao médico. Mas nunca fui. Só fui mesmo quando tive o infarte.... Ai quando eu vi aquilo doer, eu perdi a fala. Ai eu gritei, ele veio [o filho], quando ele me apanhou eu tava toda mole... Chamei o filho pra me dar um pouquinho de água e pra me levar pra o hospital que eu não tava resistindo não. Ali eu não resistia não. Só resistia, se ele me levasse pro hospital e pro médico, para o médico me dar qualquer coisa.

Eu com a dor, eu não fir nada, fiquei quieta só gemendo, ôi, $\hat{o} i$, ôi, ôi. Ainda hoje, o marido da minha sobrinha faz chateação de mim. Quando a dor começou, eu tava sentada no sofá assistindo, continuei sentada. Depois, que ela disse [a filha]: Você está morrendo. E levantei, fui no espelho, ai quando eu cheguei no espelho, en tava dessa cor, branca, toda molhada, minha roupa virou, podia torcer que caía suor. Não disse nada não, não disse nada, não. Ela [a filha] que viu. Ela tinha saído do banbeiro, ela viu. Eu disse Gicélia, eu tô com uma dor. Ai ela falou: Mamãe, você não tá com uma dor, não, você tá morrendo. Aí chamou o marido dela. Renato, a mamãe tá morrendo, venha ver a situação dela. Ai ele só foi levantando, pegando o carro.

Resistir à dor foi também uma estratégia das mulheres para se manter no cotidiano, como indivíduo que reproduz, 
de modo particular, as características básicas da sociedade, que possibilita cumprir e desfrutar o papel de mãe e de mulher:

Quando foi agora atacou de novo [a dor], mas tão dizendo que foi a emoção do casamento do meu filho. Meu filho casou, ele já tinha 10 anos de noivo, lutando para casar, lutando, coitado, sem nunca ter condição. Agora Deus ajudou ele... Eu fui para o casamento, não tava sentindo nada, cheguei na porta da igreja, esperando a noiva chegar para eu entrar na igreja com meu filho. Ai teve aquela dor, dor aqui, foi aquela dor e eu disse que ia levantar e ia na padaria beber água. Pegaram a cadeira para en sentar até a dor aliviar e eu entrar na igreja com meu filho. Mandei o menino buscar lá em casa o remédio que eu tomo, tomei duas aspirinas, e o Captopril. A noiva chegou no carro, a dor passou um pouco e eu entrei com ele

Primeiro en tava deitada, aí começou aquele negócio, aquele mal estar, aquele mal estar... Eu fui suportando até que não deu mais. Ai sai desgovernada. Eu me preocupei com meus filhos, porque são os amores da minha vida ...

Eu posso estar sentindo o que for, eu tô ali trabalhando, fazendo as coisas.

As vivências de sofrimento na trajetória de vida das mulheres parecem conferir-lhes resistência à dor, seja pela experiência da dor de parir o(a) filho(a), pelas perdas ou, ainda, pela violência e exclusão social. Transparece nas falas femininas um sentimento de força maior que se sobressai, que toma corpo, que reifica e "supervaloriza" a condição feminina. Uma espécie de poder que é concebido a quem passa pelas intempéries da condição de ser mulher-mãe, mulher-protetora da casa e da família.

A mulher suporta, a mulher suporta mesmo [a dor]. Ainda mais quem tem filho normal, como eu, que tive tantos filhos normal, tudo normal. Tive nove filhos, eu não botei ai na conta porque morreram dois... Não é mole não, viu!

A mulber é bicho duro. A dor que eu senti o bomem não aguentava não. A mulher quando diz que tá morrendo é porque tá morrendo mesmo.

Eu mesmo tenho uma capacidade muito grande de suportar a dor; se en chegar a gritar, pode acudir que eu estou morrendo, que en tive partos horriveis e en não gritava...

Qualquer dor a mulher enfrenta, corre atrás, basta que a mulher tem filho, não é? Carrega um filho nove meses, depois dos nove meses, a mulher sofre aquela dor pra botar pra fora...

A mulher, já vem no corpo dela, ela já vem com isso, eu digo isso que a mulher tem esse dom de enfrentar mais [a dor], porque ela já traz isso com ela, entende? É uma coisa que eu sempre falo... Porque a mulher dentro de casa, um monte de trabalho, enraivada, o marido maltratando e ai com aquilo ela vai ficando angustiada, a dor de ter uma criança também, é isso...

Eu passei o dia todo com dor. Quando eu cheguei da igreja me sentindo mal, me sentindo mal, ainda fui terminar de fazer as coisas, almoço, arrumar a casa, quando eu terminei de arrumar a casa que almocei, que me deitei, ai foi que a dor piorou... Quando en fui telefonar para o médico já era noite. Era uma dor tão profunda que, quando eu sentia muita raiva, eu já sofri muito na minha vida. O sofrimento da mulher é sempre mais né, é uma vida mais rigorosa...

A análise dos discursos de homens e mulheres permitiu depreender que a paralisação da resistência à dor se deu, essencialmente, diante da constatação do insuportável, da perda de controle sobre si, da percepção de que a vida ficou suspensa do cotidiano, emergindo o medo de morrer.

\section{DISCUSSÃO}

Emergiram dos relatos do grupo entrevistado afirmativas sobre a dor que retrataram um conjunto de concepções e simbolismos impregnados de estereótipos frutos do ideário feminino e masculino no meio social. Algumas destas concepções têm origem no meio familiar, apresentam-se de forma explícita ou velada, na definição ou imposição de identidades e papéis de gênero, e acabam por traduzir o pensamento hegemônico de um grupo ou parte da tradição cultural de seus membros. Boa parte destas construções começa na infância, definindo condutas de meninos e meninas e exaltam a condição masculina ou feminina e seus papéis sociais.

Assim, no caso masculino, por exemplo, certo número de brincadeiras e brinquedos, apela para pseudo "virtudes", tais como virilidade, vigor, agressividade, coragem, determinação, aventura, ação, conquista, competição, domínio pela força ou pela técnica e exaltam o "verdadeiro homem moderno"(11). Um ideal moderno, que tem uma finalidade socioeconômica e atende às exigências do mercado de trabalho no mundo globalizado e produtivo. Nesse sentido, um homem assertivo é aquele capaz de investir toda a sua força e libido no trabalho em busca de resultados, como se fosse uma máquina produtiva ${ }^{(12)}$.

As construções masculinas sobre o papel de provedor na família foi um dos temas que emergiu nos relatos masculinos e influenciou na resistência à dor. $\mathrm{O}$ discurso da paternidade como encargo social, que legitima o homem com a qualidade de provedor material tem servido de referencial para o pai, o chefe de família, que se ocupa de seu sustento. Essa construção parece incorporar-se ainda na infância, quando os meninos aprendem que lhes cabe tomar decisões sem demonstrar fraquezas. A identidade de pai, nesse sentido, vinha sendo alicerçada na identidade masculina do protetor e do pai herói. Esse papel de pai foi construído segundo padrões de gênero que vinculavam a imagem de homem ao referencial de masculinidade hegemônica. Uma condição que vem sendo questionada desde o início do movimento masculista na década de 1990. Nesse sentido era um condicionante natural a esses 
homens a relação entre ser homem, ser forte, capaz e provedor $^{(12)}$. O adágio popular, "quem casa quer casa", reforçava muito bem essa obrigação na composição masculina.

Há uma construção no imaginário social que deixa transparecer que homem não tem sentimento, não deve chorar, deve ser forte, assertivo, um ideal que reforça a frouxidão como um componente típico de quem é fraco, sensível, afeminado, de coração mole. O homem mole ${ }^{(13)}$ ou o sensível ${ }^{(12)}$ é aquele que tem sido motivo de chacota da imprensa e de uma sociedade que pode, ainda, não ter compreendido que a identidade masculina, do mesmo modo que a feminina, evoluiu. Que o homem tradicional, reconhecido pela literatura feminista ${ }^{(14)}$ como machão, não cabe mais nas expectativas sociais contemporâneas, numa cultura em desenvolvimento.

Para o imaginário social, a masculinidade ainda se constrói estável, natural, um padrão que existe numa ordem geral. A história da construção da masculinidade partiu de uma narrativa convencional da definição, internalização de normas de condutas e sentimentos apropriados para os homens, em que “[...] os rapazes são pressionados a agir e a sentir dessa forma e a se distanciar do comportamento das mulheres, das garotas e da feminilidade [...] A pressão em favor da conformidade vem das famílias, escolas, dos grupos de colegas, da mídia e, finalmente, dos empregadores". (15)

Essa rigidez na construção social da masculinidade manifesta-se de modo mais ou menos explícito pela censura feita a um jovem, por exemplo, ao escolher suas vestimentas, na forma de se relacionar com amigos, na definição por uma profissão, na exposição dos sentimentos e desejos. O estabelecimento de papéis sexuais na sociedade ajudou e ainda ajuda, até hoje, àquelas comparações e composições preconceituosas a respeito desses homens, embora já seja possível reconhecer que, como "categoria universalizante e totalizadora", não tem mais sentido.

Retomando os depoimentos sobre a resistência à dor no grupo masculino, não há nada de estranho em se acreditar que alguns destes, com comportamentos mais conformados ao modelo hegemônico masculino, tenham manifestado maior resistência e até mesmo uma psendoneutralidade ou naturalidade, ao comentar as formas de enfrentamento dessa dor, minimizando-a, ocultando-a, mantendo atividades com dor e até desconsiderando sua importância. Sob a influencia dessa composição, identificamos na nossa prática que alguns homens têm adiado a procura de cuidados médicos, o que pode também estar contribuindo para a morbidade e mortalidade pela doença.

Do mesmo modo, tal como os homens, as mulheres resistiram à dor e esse comportamento também encontra explicações nas construções sociais sobre as formas de enfrentamento e tolerância ao sofrimento por parte das mulheres.

O argumento da "naturalização" dos papéis e das diferenças sexuais faz, ainda hoje, distinção à condição feminina. Mesmo passados mais de 50 anos do início do movimento feminista, que buscou o equilíbrio de posições e condições socioeconômicas entre os gêneros nas sociedades humanas ${ }^{(14)}$. O que se vê é, ainda, uma constante busca pela descaracterização da igualdade de força e condições da mulher nas sociedades judaico-cristãs ocidentais. Mesmo assim, o estado de evolução histórica e o radicalismo ideológico de algumas facções tentaram mostrar todas as mulheres e todos os homens como únicos, insistindo-se na concepção binária de um gênero masculino e outro feminino, inflexível, imutável, na busca de posições mais privilegiadas no meio social ${ }^{(16)}$.

As vertentes da "naturalização" e das "diferenças sexuais" ainda servem para explicar a confusão nas relações entre os gêneros que alijou a mulher da política e da ciência. Há longo tempo vem-se tentando inferiorizar a sua condição biológica, sua capacidade de pensar, agir, contribuir com a evolução do ser humano e sobreviver sem as amarras masculinas ${ }^{(17)}$.

Nesse sentido, o mais forte na conjunção social vinha sendo o homem. A ele era atribuída a tarefa pesada, aquelas que envolviam desgaste físico, enfrentamentos e embates pessoais. À mulher restava o envolvimento com a emoção, o sofrimento, a representação materna, a luta doméstica para criar filhos $^{(18)}$, o assistir a doença e padecer com seus entes queridos até a morte, assim como Maria o fez com Jesus. Ela põe no mundo o filho de Deus, reconhecido pela cristandade como aquele que veio mostrar a obra do pai. No entanto, a bíblia não dá o merecido destaque ao trabalho da Virgem Maria, decisivo na criação e no calvário desse filho. Ao contrário, ela é mitificada por sua capacidade de sofrer calada, sem poder algum para interferir e redefinir o destino do seu filho. Assim, reforça-se o ideal materno na tradição judaico-cristã. Um ideal valorizado quanto aos aspectos relacionados à maternidade. Atualmente, em nossa cultura, essa valorização está voltada ao seu significado de feminilidade. Nesse prisma, a mulher verdadeira seria aquela que daria à luz e a vida por seus filhos e por sua família. Um ideal que marcou as construções sobre o feminino e que precisou ser repensado pelo movimento feminista ${ }^{(14)}$.

Do mesmo modo, a dor tem relação simbólica com o sofrimento e evolui num passado histórico que sofre a interferência da mesma cultura judaico-cristã ocidental moderna. O sofrimento que acompanha esta dor parece impregnar o imaginário social, determinando-se com base em um dualismo esquemático, separação e idealizações sobre os dois gêneros ${ }^{(10)} \mathrm{em}$ que, em dado momento, condições femininas e masculinas identificam-se mais fortes ou mais fracas, de acordo com as tarefas, papéis e posições sociais construídos e assumidos nos seus respectivos espaços de relações na comunidade.

Nesse sentido, o sofrimento vem sendo analisado no âmbito da ciência como referencial que ajuda a construir a mistificação e martirização, um ideal cristão que toca o coração e gera a compaixão de quem o observa. Investigando o Movimento Mariano no Equador, o estudo de Melhus ${ }^{(19)}$ revela que a categoria sofrimento aparece como virtude, um ideal essencialmente feminino e, como tal, reflete a experiência de vida da mulher, o que pode estar indicando que esta seja uma virtude essencialmente feminina e muito 
bem vista pela sociedade judaico-cristã, desde os seus primórdios. A condição do sofrimento não é exclusivamente analisada pela autora como o sofrimento em si, mas, pela tendência deste ser encarado como uma virtude, considerada no meio social, ainda hoje, como uma conduta moralmente boa e correta para a mulher, o que lhe ajuda a suportar a pena, a dor e o sofrimento.

Tais construções sociais podem ajudar a compreender a percepção das mulheres de que dor é para ser tolerada, restando-lhes gemer ou tentar aliviá-la com recursos próprios ou, ainda, ocultá-la. A resistência é uma forma de preservar a vida cotidiana para desempenhar o papel de mãe, mulher, avó, organizadora do espaço doméstico, esteio emocional da família, entre outros.

Fora do ambiente doméstico a mulher trabalhadora, para ser creditada é, na maioria das vezes, aquela que mais precisa provar a sua experiência da dor ${ }^{(20)}$, seja pelo choro, seja pela expressão de sofrimento. Isso parece acontecer graças ao valor atribuído à resistência ao sofrimento em relação a sua condição de mulher e de mãe na sociedade ocidental. A mulher vinha sendo preparada para passar pelas vicissitudes da dor do parto, da doença e de perdas familiares, constituindo-se no esteio emocional da família. Tal condição, de certa forma, contribuiu para compor o simbolismo da mãe no ideário social moderno.

Em estudo com mulheres com lesões por esforço repetitivo, no trabalho, constatou-se que precisaram efetivamente comprovar a existência da dor no atendimento e que a sua enfermidade perpassa toda a trajetória de trabalhodoença. Observaram-se situações em que foram obrigadas a provar a existência de suas dores e de sua doença no ambiente de trabalho, nos serviços de saúde, na previdência social e na própria família ${ }^{(20)}$.

Fazendo analogia do ideal de sofrimento com a situação dessas trabalhadoras, é possível perceber que a necessidade de provar o sofrimento se contrapõe ao ideal cristão investigado no Marianismo. Nessa nova situação no trabalho, cria-se uma expectativa de que os sintomas, a todo custo, precisam ser provados, sob pena de que, não acreditados, tais sintomas possam ser a sua própria morte. A pena de quem sofre nessa condição é não entrar no jogo do reconhecimento de valor. O sofrimento da mulher na

\section{REFERÊNCIAS}

1. Brasil. Ministério da Saúde. Indicadores de Saúde. Datasus. [Internet]. [citado 2010 Fev 1]. Disponível em: http:// tabnet.datasus.gov.br/cgi/tabcgi.exe?sim/cnv/obtbr.def

2. Potsch AA, Bassan R. O atendimento e o tratamento pré-hospitalar do infarto agudo do miocárdio. In: Timmerman A, Feitosa GS, editores. Síndromes coronárias agudas. São Paulo: Atheneu; 2003. p. 231-42.

3. Timerman S, Marques FBR, Píspico A, Ramires JAF. Tratamento pré-hospitalar da síndrome isquêmica aguda com supradesnivelamento do segmento ST: já temos suficiente evidência para implantar de rotina? Rev Soc Cardiol Estado de São Paulo. 2004;14(6):868-83. sociedade globalizada é aquele que está explícito; e, miseravelmente, se não comprovado, não caracteriza doença no trabalho. O crédito da dor e do sofrimento é diagnosticável, detém evidências e, efetivamente, é passível de controle. Uma dor ou um mal físico sem evidências tornase uma dissimulação e se converte num mal psíquico — uma somatização de cunho neurovegetativo ${ }^{(4,20)}$.

$\mathrm{Se}$, por um lado, as redes sociais e formas de enfrentamento de homens e mulheres à dor, em condições individuais e coletivas, se dão de modo positivo para resolver problemas do cotidiano, de outro, a resistência implica em risco de vida e nas incapacidades geradas, no caso em estudo, pelo infarto.

É relevante enfatizar que, diante do insuportável e da impotência no controle da dor, da impossibilidade de governar a vida no cotidiano e, portanto, sentindo medo de morrer, homens e mulheres paralisaram suas resistências à dor e recorreram ao socorro médico, mesmo que, na maioria das vezes, tardiamente.

\section{CONSIDERAÇÕES FINAIS}

O estudo evidenciou que, se no exercício dos papéis na vida cotidiana homens e mulheres constroem enfrentamento e resistência, também diante da dor se viu a presença desse comportamento como forma de manter o controle da própria existência. Como as ações de resistência à dor determinam maior risco de vida e incapacidade, são necessárias ações integradas da equipe de saúde sobre os fatores envolvidos na resistência, visando a transformá-la em uma ação que resulte em benefício para o ser humano. É necessário pensar em estratégias que mobilizem, em especial, pessoas de maior risco e próximas a elas, para valorizar a busca imediata de atendimento médico diante da dor como sintoma do infarto. A enfermeira pode atuar no plano simbólico de ambos os gêneros, visando desenvolver a percepção de que resistir à dor pode significar o risco de perder a vida ou limitá-la permanentemente. O campo de análise com base na categoria gênero, no que se refere à vivência da dor no IAM, é ainda incipiente e o aprofundamento das pesquisas poderá trazer benefícios para a prevenção da morbidade e mortalidade pela doença.

4. Mussi FC, Ferreira SL, Menezes AA. Vivências de mulheres à dor no infarto do miocárdio. Rev Esc Enferm USP. 2006;40(2):170-8.

5. Gilber WB, Gore JW, Weaver WD. Reduced time to thrombolytic delivery, but static time to presentation: the GUSTO experience from 1990 to 1997. GUSTOIII Investigators. Circulation. 1997;96 Suppl 1:201.

6. Moser DK, Kimble LP, Alberts MJ, Alonzo A, Croft JB, Dracup $K$, et al. Reducing delay in seeking treatment by patients with acute coronary syndrome and stroke: a scientific statement from the American Heart Association Council on cardiovascular nursing and stroke council. 
Circulation. 2006;114(2):168-82.

7. Weaver WD, Litwin PE, Martin JS, Kudenchuk PJ, Maynard C, Eisenberg MS, et al. Effect of age on use of trombolytic therapy and mortality in acute myocardial infarction. The MITI Project Group. J Am Coll Cardiol. 1991;18(3):657-62.

8. Mussi FC, Koizumi MS, Angelo M, Lima MS. Perda da espontaneidade da ação: o desconforto de homens que sofreram infarto agudo do miocárdio. Rev Esc Enferm USP. 2002;36(2):115-24.

9. Gómez EG, editor. Género, mujer y salud en las Américas. Washington: Organización Panamericana de la Salud, Oficina Sanitaria Panamericana, Oficina Regional de la Organización Mundial de la Salud; 1993.

10. Grossi MP, Miguel SM. A trajetória do conceito de gênero nos estudos sobre a mulher no Brasil. Calhamaço - Rev Estudos Culturais da UFSC. 1995;(2):20-4.

11. Mosse GL. L'image de l'homme. L'invention de la virilité moderne. Paris: Éditions Abbeville; 1997.

12. Pereira A. O quotidiano profissional do enfermeiro: das aparências às diferenças de gênero [tese]. Florianópolis: Universidade Federal de Santa Catarina; 1999.

13. Badinter E. XY: sobre a identidade masculina. Rio de Janeiro: Nova Fronteira; 1993.
14. Pereira A. Contribuição do paradigma feminista ao conhecimento e à prática da enfermagem. Cogitare Enferm. 1996;1(2):57-63.

15. Connell RW. Políticas da masculinidade. Educação e Realidade. 1995;20(2):185-206.

16. Oliveira PP. Discursos sobre a masculinidade. Estudos Feministas. 1998;6(1):91-112.

17. Scott J. Gênero: uma categoria útil para análise histórica. Recife: SOS Corpo; 1992.

18. Gomes NP, Diniz NMF, Araújo AJS, Freitas T. Compreendendo a violência doméstica a partir das categorias gênero e geração: revisão. Acta Paul Enferm. 2007;20(4):504-8.

19. Melhus M. Una verguenza para el honor, una verguenza para el sufrimiento. In: Palma M, organizador. Simbólica de la feminidad. La mujer en el imaginário mítico-religioso de las sociedades indias y mestiças. Quito, Equador: Ediciones Ahya-Yala; 1990. p.39-71.

20. Neves IR. LER: trabalho, exclusão, dor, sofrimento e relação de gênero. Um estudo com trabalhadoras atendidas num serviço público de saúde. Cad Saúde Pública. 2006;22(6):1257-65. 